\title{
Echo response and clinical outcome in CRT patients
}

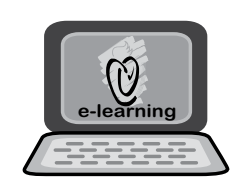

\author{
J. van 't Sant $\cdot$ T.P. Mast $\cdot$ M.M. Bos $\cdot$ I.A. ter Horst • \\ W.M. van Everdingen $\cdot$ M. Meine $\cdot$ M.J. Cramer
}

Published online: 7 December 2015

(C) The Author(s) 2015. This article is published with open access at Springerlink.com

\begin{abstract}
Background Change in left ventricular end-systolic volume ( $\triangle \mathrm{LVESV}$ ) is the most frequently used surrogate marker in measuring response to cardiac resynchronisation therapy (CRT). We investigated whether $\triangle$ LVESV is the best measure to discriminate between a favourable and unfavourable outcome and whether this is equally applicable to non-ischaemic and ischaemic cardiomyopathy.

Methods 205 CRT patients (age $65 \pm 12$ years, $69 \%$ men) were included. At baseline and 6 months echocardiographic studies, exercise testing and laboratory measurements were performed. CRT response was assessed by: $\triangle \mathrm{LVESV}, \Delta \mathrm{LV}$ ejection fraction (LVEF), $\Delta$ interventricular mechanical delay, $\Delta \mathrm{VO}_{2}$ peak, $\Delta \mathrm{VE} / \mathrm{VCO}_{2}, \Delta \mathrm{BNP}, \Delta$ creatinine, $\Delta \mathrm{NYHA}$, and $\triangle \mathrm{QRS}$. These were correlated to the occurrence of major adverse cardiac events (MACE) between 6 and 24 months. Results MACE occurred in $19 \%$ of the patients (non-ischaemic: $13 \%$, ischaemic: $24 \%$ ). $\triangle$ LVESV remained the only surrogate marker for CRT response for the total population and patients with non-ischaemic cardiomyopathy, showing areas under the curve (AUC) of 0.69 and 0.850 , respectively. For ischaemic cardiomyopathy, $\triangle \mathrm{BNP}$ was the best surrogate marker showing an AUC of 0.66.

Conclusion $\triangle \mathrm{LVESV}$ is an excellent surrogate marker measuring CRT response concerning long-term outcome for non-ischaemic cardiomyopathy. $\triangle$ LVESV is not suitable for ischaemic cardiomyopathy in which measuring CRT response remains difficult.
\end{abstract}

J. van 't Sant $(\bowtie) \cdot$ T.P. Mast · M.M. Bos · I.A. ter Horst ·

W.M. van Everdingen · M. Meine · M.J. Cramer

Department of Cardiology, University Medical Center Utrecht,

Heidelberglaan 100,

3584 CX Utrecht, The Netherlands

e-mail: j.vantsant@gmail.nl
Keywords Cardiac resynchronisation therapy · Surrogate markers

\section{Background}

Cardiac resynchronisation therapy (CRT) reduces major adverse cardiac events (MACE), and improves exercise capacity and functional class, in drug refractory heart failure patients $(\mathrm{NYHA} \geq \mathrm{II})$ with ventricular conduction delay [1-3]. However, the degree of CRT response varies widely and ranges from MACE rates similar to heart failure patients without CRT to rates comparable with a matched sample from the general population $[4,5]$. In daily clinical practice, degree of CRT response is assessed 6 months after CRT implantation using echocardiographic change $(\Delta)$ of left ventricular end-systolic volume (LVESV) [6]. However, whether $\triangle \mathrm{LVESV}$ is the most appropriate surrogate marker has not been extensively investigated. Furthermore, due to differences in underlying disease, response measures might not be equally appropriate for patients with non-ischaemic and ischaemic cardiomyopathy.

Two basic criteria need to be fulfilled for a variable to be a suitable surrogate marker: (1) A relation has to be demonstrated between the change of the surrogate marker over time (e.g. LVESV decrease) and the true endpoint (MACE), and (2) a pathophysiological foundation must be known to consider the surrogate marker as a main determinant of the true endpoint [7]. LVESV declines after CRT due to reverse remodelling and has been demonstrated to correlate with a favourable prognosis $[8,9]$. Besides change in LV volume, changes in parameters indicating LV systolic function, mechanical dyssynchrony, cardiopulmonary condition and biomarkers of overall cardiovascular function are potential surrogate markers for CRT response [10-17]. 
In this study we investigated (1) several surrogate markers for CRT response, and (2) whether these surrogate markers were equally applicable for non-ischaemic and ischaemic cardiomyopathy.

\section{Methods}

Study design and cohort

This was a retrospective study in which we included 205 consecutive patients who received a CRT device (200 received a CRT defibrillator and four a CRT pacemaker) in the University Medical Center Utrecht (UMCU) between August 2005 and August 2011, with prospectively planned echocardiographic studies, cardiopulmonary exercise testing and laboratory evaluation available before implantation. It was recommended not to change device settings during the first 6 months. Configurations were only adjusted by exception, during regular check-up at 2 months. Thereafter, until the six-month point of assessment, pacing configurations remained unchanged.

Six months after device implantation, evaluation of the echocardiographic studies, cardiopulmonary exercise testing and laboratory tests was repeated. To determine the best surrogate marker for CRT response, the correlation between all potential surrogate CRT response measurements and MACE occurring between 6 and 24 months was assessed. We did not include MACE occurring before our six-month evaluation point, as therapy effect was quantified at 6 months in order to gather prognostic information for the period afterwards, not the preceding period. In addition, the effect of CRT might not yet be optimal in the preceding period, which was another reason why we chose not to include MACE occurring in the first 6 months to correlate to surrogate response measurements. The study was conducted in accordance with the Declaration of Helsinki.

Response to CRT was assessed 6 months after device implantation by (1) $\triangle$ LVESV (\%), (2) $\Delta$ left ventricular ejection fraction (LVEF; absolute \%), (3) $\Delta$ interventricular mechanical delay (IVMD; ms), (4) $\Delta \mathrm{VO}_{2}$ peak $(\mathrm{ml} / \mathrm{kg} /$ $\min$ ), (5) $\Delta$ percentage of predicted $\mathrm{VO}_{2}$ peak (absolute $\%$ ), (6) $\Delta \mathrm{VE} / \mathrm{VCO}_{2}$ slope, (7) $\Delta$ brain natriuretic peptide (BNP; $\mathrm{pmol} / \mathrm{L}),(8) \Delta$ creatinine $(\mu \mathrm{mol} / \mathrm{L}), \Delta \mathrm{NYHA}$, and $\Delta \mathrm{QRS}$ duration.

\section{Echocardiography}

Data were acquired using Philips IE 33 (Philips Medical Systems, Andover, Massachusetts, USA) or Vivid 7 (General Electric, Milwaukee, USA) ultrasound machines. Echocardiographic parameters were assessed using Xcelera software (R3.3L1). Volumes and ejection fraction were assessed by Simpsons' biplane method in accordance with the guidelines of the American Society of Echocardiography (ASE) and European Association of Echocardiography (EAE) [10].

Doppler flows over the pulmonary and aortic valve were recorded and time from $\mathrm{Q}$ to onset of flow was assessed for both valves. IVMD was defined as the time span between opening of the aortic valve and the pulmonary valve [6]. Measurements were performed on three separate beats, or five beats in case of irregular rhythms.

\section{Cardiopulmonary exercise testing}

Cardiopulmonary exercise testing on the bicycle ergometer started with unloaded cycling for 2 min after which a protocol of stepwise incremental exercise was applied, starting at $25 \mathrm{~W}$ with increments of 5,10 or $15 \mathrm{~W}$ every minute depending on the estimated maximum workload. Rotation speed was kept around 60 per minute. Prior to testing, gas and flow sensors were calibrated utilising gases with established concentrations of $\mathrm{O}_{2}$ and $\mathrm{CO}_{2}$.

Ventilation (VE) (L/min), peak oxygen consumption $\left(\mathrm{VO}_{2}\right)(\mathrm{mL} / \mathrm{kg} / \mathrm{min})$, and carbon dioxide production $\left(\mathrm{VCO}_{2}\right)$ (L/min) were measured for each patient throughout the exercise on a breath-to-breath basis. $\mathrm{VO}_{2}$ peak and $\mathrm{VE} /$ $\mathrm{VCO}_{2}$ slope were assessed. Data for the $\mathrm{VE} / \mathrm{VCO}_{2}$ slope were collected throughout the exercise, with exclusion of the unloaded cycling and recovery period.

$\mathrm{VO}_{2}$ peak is the level of $\mathrm{O}_{2}$ consumption during maximum effort and averaged over a 30 -second period [11]. The $\mathrm{VE} / \mathrm{VCO}_{2}$ slope provides a measure of $\mathrm{CO}_{2}$ exchange efficiency by assessing required ventilation for $\mathrm{CO}_{2}$ elimination [11].

Long-term follow-up and assessment of major adverse cardiac events

MACE was defined as: hospital admission for heart failure, sustained ventricular tachycardia (VT) (VT lasting $>30 \mathrm{~s}$ or a VT beneath the monitoring zone leading to hospitalisation), ventricular fibrillation (VF), receiving a left ventricular assist device (LVAD), undergoing heart transplantation, death due to heart failure and appropriate implantable cardioverter defibrillator (ICD) shocks (due to VT or VF). Multicentre studies proved a CRT defibrillator was beneficial over a CRT pacemaker device concerning long-term survival, indicating that the shock function of the defibrillator prevents MACE in a heart failure population and therefore an appropriate shock was considered as an adverse cardiac event [12]. 
Statistical analyses

Statistical analysis was performed using SPSS version 20.0 (SPSS Inc., Chicago, Illinois). Continuous variables are presented as mean with standard deviation (SD) when normally distributed (mean $\pm \mathrm{SD}$ ) and as median with interquartile range (IQR) in case of non-normal distribution (median (IQR)). Distributions were checked using Q-Q plots. Categorical variables are presented as numbers and percentages.

Surrogate markers of CRT response were assessed for the total population, and the ischaemic and non-ischaemic subpopulations. Data were compared with a T-test or MannWhitney $\mathrm{U}$ test in case of non-normal distribution. A $p$-value of $<0.05$ was considered statistically significant. Surrogate markers demonstrating a significant difference between patients with and without MACE were subsequently tested using univariable and multivariable Cox backward logistic regression analyses. Areas under the receiveroperating curve (AUC) were assessed with respect to the occurrence of MACE. Subsequently, Cox regression multivariable analyses were performed to evaluate the association between significant surrogate markers and time to first MACE. These analyses were performed for the total population, ischaemic and non-ischaemic subpopulations. Multicollinearity amongst variables was checked using variance inflation factors, and a value of $>5$ was considered evidence of multicollinearity. Furthermore, the relation between surrogate markers of CRT response and MACE was calculated by the Kaplan-Meier method and compared by means of the log-rank test. A two-tailed probability value of $p<0.05$ was considered statistically significant.

\section{Results}

Baseline results

Baseline characteristics are listed in Table 1. Mean age $65 \pm 12$ years, $69 \%(n=142)$ male, $52 \%(n=106)$ with ischaemic cardiomyopathy. At baseline, LVESV was 180 (87) $\mathrm{mL}$, LVEF $22 \pm 7 \%$, and IVMD $46 \pm 28 \mathrm{~ms}$. Baseline $\mathrm{VO}_{2}$ peak was $14 \pm 4 \mathrm{ml} / \mathrm{kg} / \mathrm{min}$, predicted $\mathrm{VO}_{2}$ peak $61 \pm 19 \%$ and $\mathrm{VE} / \mathrm{VCO}_{2}$ slope 38 (15). Baseline BNP levels were 112 (172) $\mathrm{pmol} / \mathrm{L}$ and creatinine levels were 112 (52) $\mu \mathrm{mol} / \mathrm{L}$.

\section{Six-month results}

Six-month follow-up values are listed in Table 1. At sixmonth follow-up LVESV was 133 (95) ml, LVEF 29 $10 \%$, and IVMD was $15 \pm 28 \mathrm{~ms}$. $\mathrm{VO}_{2}$ peak was $15 \pm 5 \mathrm{ml} / \mathrm{kg} / \mathrm{min}$, predicted $\mathrm{VO}_{2}$ peak $67 \pm 23 \%$ and $\mathrm{VE} / \mathrm{VCO}_{2}$ slope 34 (11). BNP levels were 71 (107) pmol/L and creatinine levels were 115 (53) $\mu \mathrm{mol} / \mathrm{L}$.
Table 1 Baseline and six-month follow-up parameters

\begin{tabular}{|c|c|c|c|}
\hline & $\begin{array}{l}\text { Baseline } \\
(n=205)\end{array}$ & $\begin{array}{l}\text { Six-month } \\
\text { FU }(n=197)\end{array}$ & $P$-value \\
\hline \multicolumn{4}{|l|}{ Clinical } \\
\hline Age, mean $\pm \mathrm{SD}$ (years) & $64.8 \pm 12.4$ & - & \\
\hline Male gender (\%) & $142(69)$ & - & \\
\hline Ischaemic cardiomyopathy (\%) & $106(52 \%)$ & - & \\
\hline NYHA I (\%) & $1(0.5)$ & $16(8.3)$ & 0.001 \\
\hline NYHA II (\%) & $26(12.7)$ & $104(53.6)$ & 0.171 \\
\hline NYHA III (\%) & $167(81.5)$ & $71(36.6)$ & 0.062 \\
\hline NYHA IV (\%) & $11(5.3)$ & $3(1.5)$ & $<0.001$ \\
\hline \multicolumn{4}{|l|}{ ECG } \\
\hline $\mathrm{QRS}$ duration, mean $\pm \mathrm{SD}$, ms & $166 \pm 24$ & $153 \pm 24$ & $<0.001$ \\
\hline Left bundle branch block (\%) & $116(57)$ & - & \\
\hline $\begin{array}{l}\text { Interventricular conduction } \\
\text { delay }(\%)\end{array}$ & $63(31)$ & - & \\
\hline Right bundle branch block (\%) & $1(0.5)$ & - & \\
\hline $\mathrm{QRS}<120 \mathrm{~ms}(\%)$ & $1(0.5)$ & - & \\
\hline Right ventricular pacing (\%) & $23(11)$ & - & \\
\hline \multicolumn{4}{|l|}{ Echocardiography } \\
\hline LVESV, median (IQR), ml & $180(87)$ & $133(95)$ & $<0.001$ \\
\hline LVEDV, median (IQR), ml & $230(92)$ & $182(115)$ & $<0.001$ \\
\hline $\mathrm{LVEF}$, mean \pm SD $(\%)$ & $21.6 \pm 6.8$ & $28.6 \pm 10.4$ & $<0.001$ \\
\hline $\mathrm{IVMD}$, mean $\pm \mathrm{SD}(\mathrm{ms})$ & $46 \pm 28$ & $15 \pm 28$ & $<0.001$ \\
\hline \multicolumn{4}{|l|}{ Exercise test } \\
\hline $\begin{array}{l}\text { Peak } \mathrm{VO}_{2} \text {, mean } \pm \mathrm{SD}(\mathrm{ml} / \mathrm{kg} / \\
\text { min) }\end{array}$ & $14.0 \pm 4.2$ & $15.4 \pm 4.8$ & $<0.001$ \\
\hline $\begin{array}{l}\text { Percentage of predicted peak } \\
\mathrm{VO}_{2} \text {, mean } \pm \mathrm{SD}(\%)\end{array}$ & $61.1 \pm 18.8$ & $67.4 \pm 23.2$ & $<0.001$ \\
\hline $\mathrm{VE} / \mathrm{VCO}_{2}$, median (IQR) & $38(15)$ & $34(11)$ & $<0.001$ \\
\hline \multicolumn{4}{|l|}{ Laboratory tests } \\
\hline BNP, median (IQR), pmol/L & $112(172)$ & $71(107)$ & $<0.001$ \\
\hline $\begin{array}{l}\text { Creatinine, median (IQR), } \\
\mu \mathrm{mol} / \mathrm{L}\end{array}$ & $112(52)$ & $115(53)$ & 0.002 \\
\hline \multicolumn{4}{|l|}{ Medication } \\
\hline Beta-blocker (\%) & $157(78)$ & - & \\
\hline ACE-inhibitor (\%) & $152(76)$ & - & \\
\hline Diuretics (\%) & $180(90)$ & - & \\
\hline
\end{tabular}

$B N P$ brain natriuretic peptide, $F U$ follow-up, $I V M D$ interventricular mechanical delay, $L V E F$ left ventricular ejection fraction, $L V E D V$ left ventricular end-diastolic volume, LVESV left ventricular endsystolic volume, $\mathrm{NYHA}$ New York Heart Association, $\mathrm{VO}_{2}$ oxygen consumption, $V E / V C \mathrm{O}_{2} \mathrm{CO}_{2}$ exchange efficiency.

Long-term follow-up and major adverse cardiac events

Six patients died before six-month follow-up, one patient had undergone a heart transplant and one received an LV assist device; these patients were not included for further analyses. Of the remaining 197 patients, four patients were lost to follow-up, two died of a non-cardiac cause and one died of an unknown cause (Fig. 1). Between 6 and 24 months 19\% $(36 / 190)$ experienced at least one MACE. Twenty patients had a hospital admission due to heart failure, nine had ventricular arrhythmias, and seven died due to heart failure. Of 
Figure 1 Flow chart of inclusion. CRT therapy between 2005-2011 and prospectively planned baseline and 6 months CPX and echocardiography. $C R T$ cardiac resynchronization therapy, $C P X$ cardiopulmonary exercise testing, LVAD left ventricular assist device

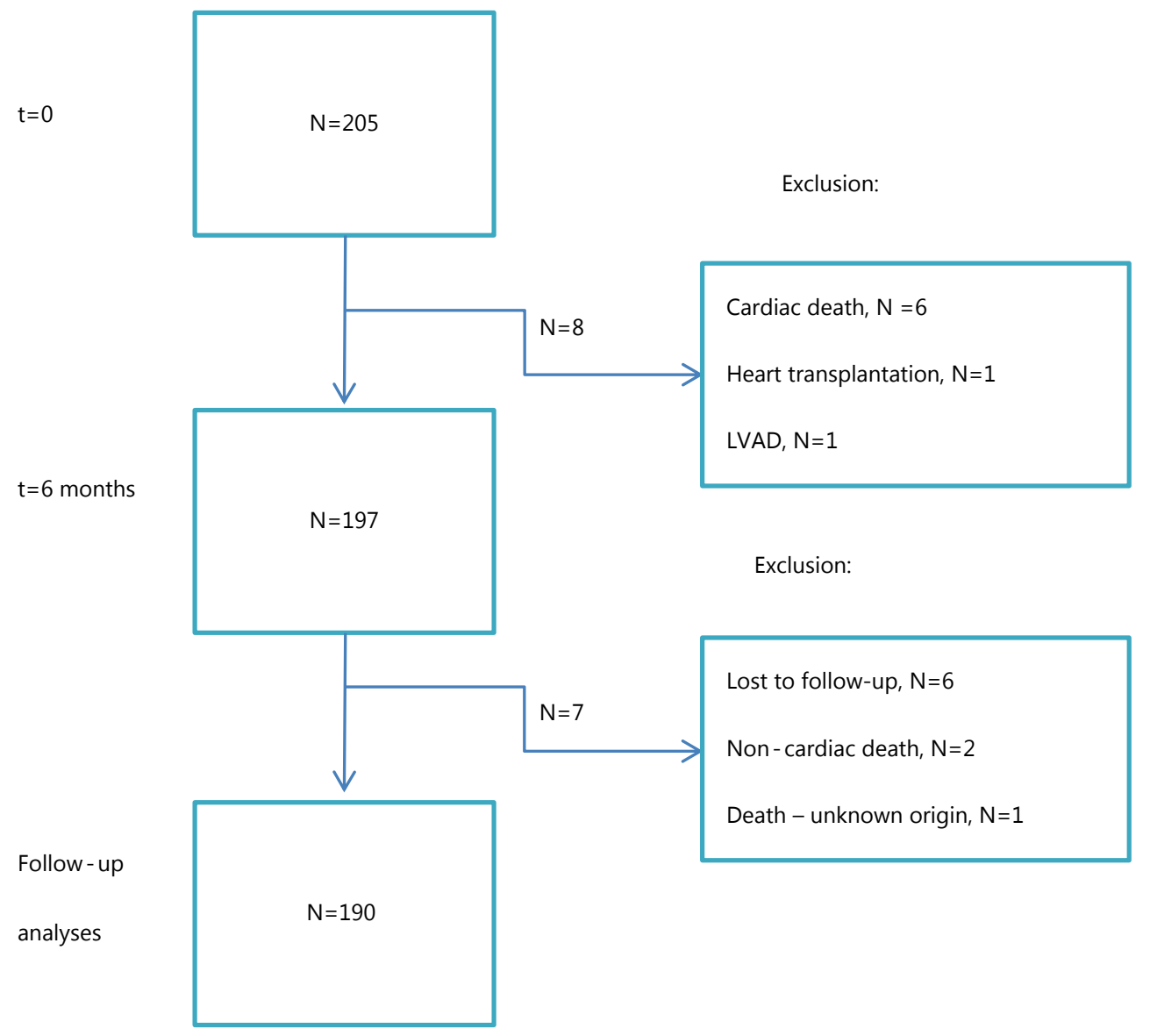

Abbreviations: $C R T=$ cardiac resynchronization therapy, $C P X=$ cardiopulmonary exercise testing, $L V A D=$ left ventricular assist device the ischaemic patients $24 \%(n=24)$ experienced a MACE versus $13 \%(n=12)$ of non-ischaemic patients $(p=0.061)$.

\section{Assessment of CRT response}

$\triangle \mathrm{LVESV}, \triangle \mathrm{LVEF}$, and $\triangle \mathrm{BNP}$ differed significantly between patients with and without MACE in the total population (Table 2). After multivariable analyses, LVESV remained the only surrogate marker for CRT response significantly correlated to the occurrence of MACE. Discriminative performance of this surrogate marker was moderate: AUC $=0.69$ (Table 3 and Fig. 2).

Associations between surrogate response markers and MACE differed among heart failure aetiologies (Table 3, Table 4 and 5). In the non-ischaemic cardiomyopathy population results were in concordance with the total population as $\triangle \mathrm{LVESV}$ remained the only surrogate marker for CRT response (Table 4). Discriminative power of $\triangle \mathrm{LVESV}$ was high in this subpopulation: $\mathrm{AUC}=0.85$ (Fig. 1 and Fig. 3a).

In the ischaemic cardiomyopathy population no significant correlation was found between $\triangle L V E S V$ and the occurrence of MACE (Fig. 3b). In this group $\triangle \mathrm{BNP}$ was the only independent surrogate marker for CRT response (Table 5). Discriminative power was moderate with AUC 0.66.

Concerning Fig. 2, a $15 \%$ cut-off for $\triangle$ LVESV was chosen, as this is the most often used cut-off value to discriminate between responders and non-responders [6, 9].

\section{Discussion}

For the total population, $\triangle \mathrm{LVESV}$ was the most reliable surrogate marker for CRT response. Especially in the non-ischaemic cardiomyopathy population, this parameter showed excellent performance for discriminating between favourable and unfavourable long-term outcome. However, we demonstrated that $\triangle \mathrm{LVESV}$ is a poor surrogate marker for CRT response in patients with ischaemic cardiomyopathy. In this group of patients $\triangle \mathrm{LVESV}$ was unable to indicate which patients had a favourable and which had an unfavourable long-term outcome. These findings are of utmost importance as $\triangle \mathrm{LVESV}$ is frequently chosen as outcome measure to assess response to CRT treatment regardless of aetiology $[6,13]$. 
Table 2 Comparison of changes in echocardiographic, cardiopulmonary, and laboratory parameters between patients with and without a MACE

\begin{tabular}{llll}
\hline Potential surrogate endpoints & $\begin{array}{l}\text { MACE } \\
(n=36)\end{array}$ & $\begin{array}{l}\text { Non-MACE } \\
(n=154)\end{array}$ & $P$-value \\
\hline$\Delta$ LVESV (\%) & $-9.5 \pm 18.7$ & $-23.5 \pm 23.0$ & $<0.001$ \\
$\Delta$ LVEF (absolute \%) & $3.5 \pm 6.2$ & $8.2 \pm 9.0$ & $<0.001$ \\
$\Delta$ IVMD (ms) & $-29 \pm 35$ & $-34 \pm 32$ & 0.422 \\
$\Delta$ QRS duration (ms) & $4.0 \pm 28.4$ & $16.4 \pm 26.3$ & 0.022 \\
$\Delta$ Peak VO, (mI/kg/min) & $0.8 \pm 3.0$ & $1.1 \pm 3.1$ & 0.684 \\
$\Delta$ Predicted peak VO, (absolute \%) & $5.7 \pm 14.7$ & $6.0 \pm 14.8$ & 0.930 \\
$\Delta$ VE/VCO, slope & $-2(17)$ & $-4(9)$ & 0.674 \\
$\Delta$ BNP (pmol/L) & $14.5(125)$ & $-21.5(106)$ & 0.019 \\
$\Delta$ Creatinine ( $\mu$ mol/L) & $0.5(23)$ & $-4.8(22)$ & 0.375 \\
NYHA improvement (\%) & $12(38)$ & $94(63 \%)$ & 0.009
\end{tabular}

$\triangle$ indicates a change, $B N P$ brain natriuretic peptide, $I C M$ ischaemic cardiomyopathy, IVMD interventricular mechanical delay, LVEF left ventricular ejection fraction, LVESV left ventricular end-systolic volume, $M A C E$ major adverse cardiac events, NYHA New York Heart Association, $N I C M$ non-ischaemic cardiomyopathy, $V O_{2}$ oxygen consumption, $V E / V C O$, $\mathrm{CO}_{2}$ exchange efficiency.

Surrogate markers in non-ischaemic cardiomyopathy

For non-ischaemic cardiomyopathy, $\triangle \mathrm{LVESV}$ was the best surrogate marker in our study. The importance of change in LV volume during CRT over other surrogate markers has been demonstrated previously and seems to be in concordance with our data $[8,14]$. $\triangle$ LVESV was independent of change in LV systolic function, cardiopulmonary condition, mechanical dyssynchrony and cardiovascular biomarkers.

The clinical course of heart failure is determined by cardiac remodelling [15]. A decrease in LVESV implies reverse remodelling because it reflects both structural (reverse) remodelling and increased fibre shortening. LVEF, as a parameter for LV systolic function, seems less suitable as surrogate marker, probably because it is more dependent on LV end-diastolic volume and heart rate [15].

A change of mechanical dyssynchrony was not an appropriate surrogate outcome marker either. Mechanical dyssynchrony is not obligatory to be eligible for CRT implantation $[16,17]$. Consequently, IVMD at baseline, and its reduction, showed a wide distribution in our study cohort, making $\triangle I V M D$ an unsuitable surrogate marker.

Cardiopulmonary exercise testing parameters may take longer to improve than 6 months. It has been demonstrated in heart failure patients that during a training programme time to reach maximum improvement varied between 16 and 26 weeks [18]. This process probably takes even longer without training, when it is solely influenced by CRT.

Also, neither $\triangle \mathrm{BNP}$ nor $\Delta$ creatinine could identify those with a favourable or unfavourable long-term outcome in the non-ischaemic cardiomyopathy group. $\triangle \mathrm{BNP}$ may not be reliable due to a wide distribution and high day-to-day variability [19]. Renal function does not seem to be affected
Table 3 Multivariable Cox regression concerning surrogate endpoints and MACE for the total population, non-ischaemic and ischaemic subpopulations

\begin{tabular}{llll}
\hline $\begin{array}{l}\text { Potential surro- } \\
\text { gate endpoints }\end{array}$ & \multicolumn{3}{l}{ Multivariable HR (CI) } \\
\hline & $\begin{array}{l}\text { Total } \\
\text { population }\end{array}$ & NICM & ICM \\
& & \\
$\Delta$ LVESV (\%) & 0.975 & 0.960 & - \\
& $(0.960-0.991)$ & $(0.938-0.983)$ & \\
$\Delta$ LVEF & - & - & - \\
$(\mathbf{a b s o l u t e ~ \% ) ~}$ & & & \\
$\begin{array}{l}\Delta \text { VE/VCO } \\
\text { slope }\end{array}$ & - & - & - \\
$\Delta$ BNP (pmol/L) & - & - & 0.993 \\
& & $-0.988-0.998)$
\end{tabular}

$\triangle$ NYHA (class) -

$\triangle$ indicates a change, $B N P$ brain natriuretic peptide, $I C M$ ischaemic cardiomyopathy, IVMD interventricular mechanical delay, $L V E F$ left ventricular ejection fraction, $L V E S V$ left ventricular end-systolic volume, MACE major adverse cardiac events, NYHA New York Heart Association, NICM non-ischaemic cardiomyopathy, $\mathrm{VO}_{2}$ oxygen consumption, $\mathrm{VE} / \mathrm{VCO} \mathrm{CO}_{2}$ exchange efficiency.

by CRT as both groups showed only minor changes in creatinine between baseline and 6 months. This is in line with a recent study [20]. Moreover, when stratified according to baseline renal function, patients demonstrating either an improvement or decline in renal function occurred for all disease stages and changes were therefore unpredictable [20]. Consequently, changes in renal function can probably not discriminate between favourable and unfavourable clinical outcome.

Surrogate markers in ischaemic cardiomyopathy

A remarkable finding was that $\triangle \mathrm{LVESV}$ in ischaemic cardiomyopathy could not distinguish between patients who remained free of MACE during follow-up. Although $\triangle \mathrm{BNP}$ was the best surrogate marker in this subpopulation, it was unsuitable for good discrimination. This implicates that ischaemic cardiomyopathy is influenced by other factors when it comes to long-term outcome.

Although both aetiologies are characterised by reduced contractility and global dilation, the disease substrate differs greatly. In ischaemic cardiomyopathy, coronary artery disease is the pathophysiological substrate and a high variety exists concerning the extent of disease, affecting prognosis, and making this a very heterogeneous group [21].

Furthermore, it has been demonstrated that scar tissue is a more important determinant of long-term outcome in ischaemic cardiomyopathy than contractile reserve [22]. This is also confirmed by the current study. As BNP is mainly produced by cardiomyocytes [23], it could be hypothesised that BNP change is only possible in patients with significant amounts of myocytes left, and consequently less scar tissue. Also, presence of myocardial scar in the pacing region 


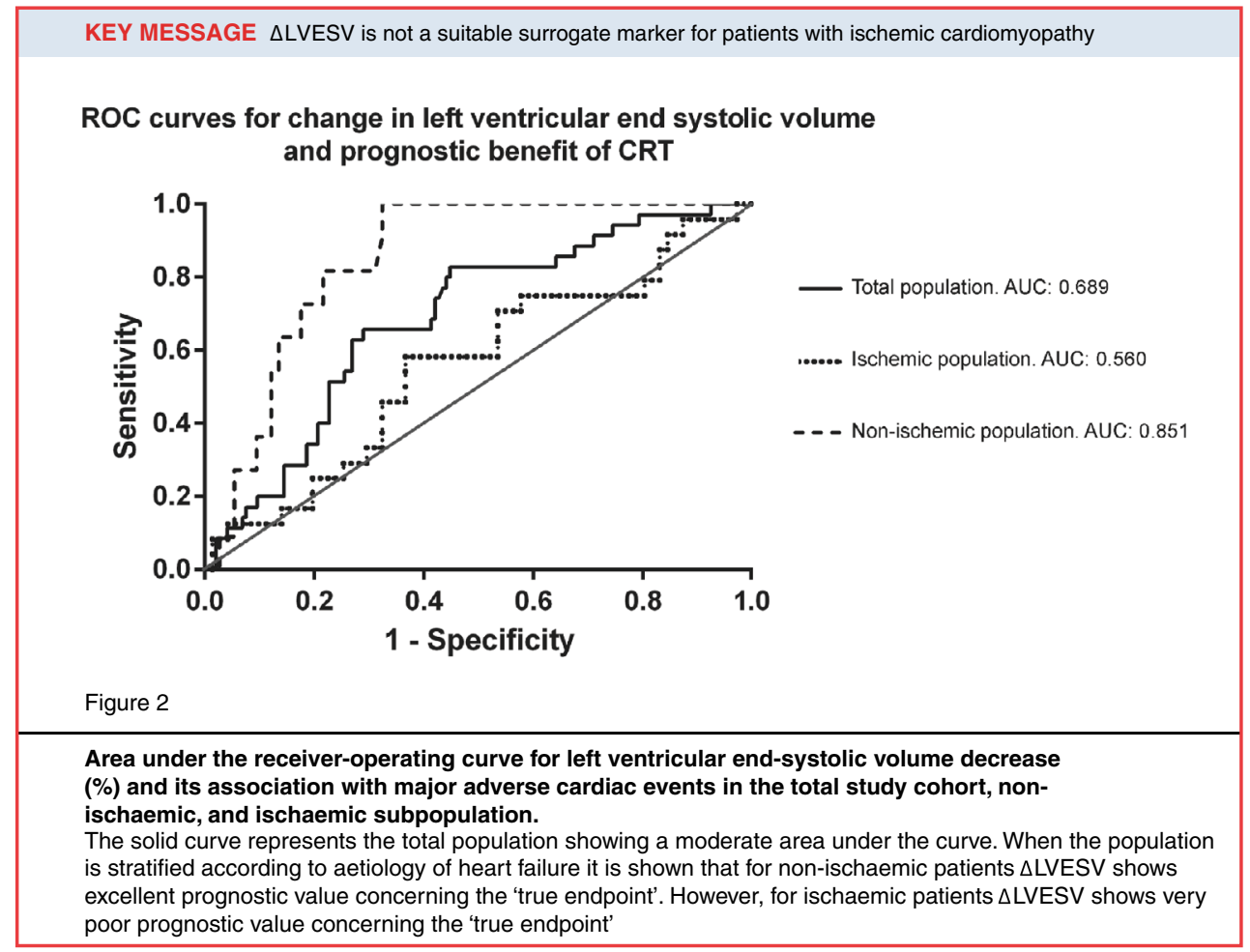

Table 4 Comparison of changes in echocardiographic, cardiopulmonary, and laboratory parameters between patients with non-ischaemic cardiomyopathy with and without a MACE

\begin{tabular}{|c|c|c|c|}
\hline $\begin{array}{l}\text { Potential surrogate } \\
\text { endpoints }\end{array}$ & $\begin{array}{l}\text { MACE } \\
(n=11)\end{array}$ & $\begin{array}{l}\text { Non-MACE } \\
(n=74)\end{array}$ & $P$-value \\
\hline$\overline{\Delta \text { LVESV (\%) }}$ & $-2.4 \pm 11.5$ & $-30.0 \pm 24.2$ & $<0.001$ \\
\hline$\Delta$ LVEF (absolute \%) & $3.5 \pm 6.2$ & $10.9 \pm 9.3$ & 0.013 \\
\hline$\Delta$ IVMD (ms) & $-35 \pm 37$ & $-37 \pm 34$ & 0.832 \\
\hline$\Delta \mathbf{Q R S}$ duration (ms) & $3.6 \pm 28.0$ & $17.6 \pm 28.2$ & 0.132 \\
\hline$\Delta$ Peak VO $2(\mathrm{ml} / \mathrm{kg} / \mathrm{min})$ & $2.2 \pm 2.9$ & $1.36 \pm 3.5$ & 0.615 \\
\hline $\begin{array}{l}\Delta \text { Predicted peak } \mathrm{VO}_{2} \\
\text { (absolute \%) }\end{array}$ & $12.4 \pm 15.1$ & $6.7 \pm 16.0$ & 0.365 \\
\hline$\Delta \mathrm{VE} / \mathrm{VCO}_{2}$ slope & $10(19)$ & $3(6)$ & 0.049 \\
\hline$\Delta \mathrm{BNP}(\mathrm{pmol} / \mathrm{L})$ & $-14(360)$ & $32(106)$ & 0.627 \\
\hline$\Delta$ Creatinine $(\mu \mathrm{mol} / \mathrm{L})$ & $5.0(29)$ & $-1.5(22)$ & 0.159 \\
\hline NYHA improvement (\%) & $6(60)$ & $50(66)$ & 0.718 \\
\hline
\end{tabular}

$\triangle$ indicates a change, $B N P$ brain natriuretic peptide, $I C M$ ischaemic cardiomyopathy, IVMD interventricular mechanical delay, $L V E F$ left ventricular ejection fraction, $L V E S V$ left ventricular end-systolic volume, $M A C E$ major adverse cardiac events, NYHA New York Heart Association, NICM non-ischaemic cardiomyopathy, $V O$, oxygen consumption, $\mathrm{VE} / \mathrm{VCO}_{2} \mathrm{CO}_{2}$ exchange efficiency.

was another important determinant of long-term outcome in patients with ischaemic cardiomyopathy eligible for CRT [24].

In addition, in about $25 \%$ of patients disease extends beyond the coronary arteries and also affects the brain and peripheral tissues, which may affect prognosis independent of the amount of cardiac remodelling [25]. Therefore, it might be important to assess overall atherosclerotic status
Table 5 Comparison of changes in echocardiographic, cardiopulmonary, and laboratory parameters between patients with ischaemic cardiomyopathy with and without a MACE

\begin{tabular}{|c|c|c|c|}
\hline $\begin{array}{l}\text { Potential surrogate } \\
\text { end-points }\end{array}$ & $\begin{array}{l}\text { MACE } \\
(n=24)\end{array}$ & $\begin{array}{l}\text { Non-MACE } \\
(n=71)\end{array}$ & $P$-value \\
\hline$\triangle$ LVESV (\%) & $-12.7 \pm 20.5$ & $-16.8 \pm 19.8$ & 0.392 \\
\hline$\Delta$ LVEF (absolute \%) & $3.5 \pm 6.3$ & $5.5 \pm 7.8$ & 0.269 \\
\hline$\Delta$ IVMD (ms) & $-26 \pm 35$ & $-31 \pm 31$ & 0.537 \\
\hline$\Delta \mathbf{Q R S}$ duration (ms) & $4.3 \pm 29.3$ & $15.1 \pm 24.3$ & 0.101 \\
\hline$\Delta$ Peak VO $2(\mathrm{ml} / \mathrm{kg} / \mathrm{min})$ & $0.1 \pm 2.8$ & $0.8 \pm 2.5$ & 0.299 \\
\hline $\begin{array}{l}\Delta \text { Predicted peak } \mathrm{VO}_{2} \\
\text { (absolute \%) }\end{array}$ & $2.7 \pm 13.9$ & $5.3 \pm 13.6$ & 0.496 \\
\hline$\Delta \mathrm{VE} / \mathrm{VCO}_{2}$ slope & $0.7(18)$ & $4.4(13)$ & 0.139 \\
\hline$\Delta \mathrm{BNP}(\mathrm{pmol} / \mathrm{L})$ & $35(77)$ & $-53(78)$ & 0.041 \\
\hline$\Delta$ Creatinine $(\mu \mathrm{mol} / \mathrm{L})$ & $-6.0(27)$ & $-5.0(22)$ & 0.673 \\
\hline NYHA improvement (\%) & $6(27)$ & $44(60)$ & 0.008 \\
\hline
\end{tabular}

$\overline{\triangle \text { indicates a change, } B N P \text { brain natriuretic peptide, } I C M \text { ischaemic }}$ cardiomyopathy, IVMD interventricular mechanical delay, $L V E F$ left ventricular ejection fraction, $L V E S V$ left ventricular endsystolic volume, MACE major adverse cardiac events, NYHA New York Heart Association, $\mathrm{NICM}$ non-ischaemic cardiomyopathy, $\mathrm{VO}_{2}$ oxygen consumption, $V E / V C O{ }_{2} \mathrm{CO}_{2}$ exchange efficiency.

before CRT implantation. Importantly, these results do not imply that CRT is not beneficial for patients with ischaemic cardiomyopathy.

\section{Prediction of MACE}

Although the present study searched for the best surrogate markers for CRT response through a correlation with 


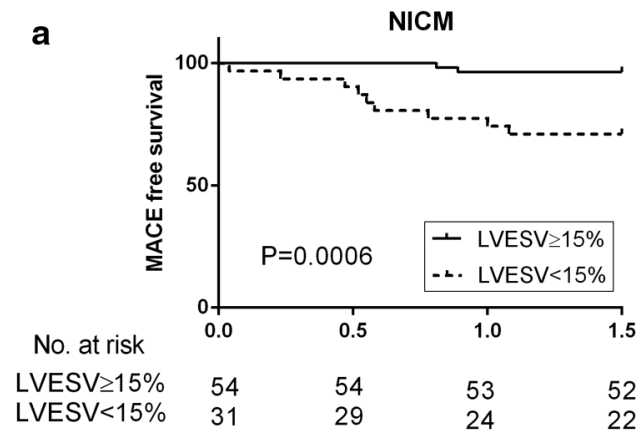

Figure 3 a Kaplan-Meier estimates of survival in non-ischaemic subjects stratified by amount of left ventricular end-systolic volume decrease. A $15 \%$ cut-off for $\triangle \mathrm{LVESV}$ was chosen, as this is the most often used cut-off value to discriminate between responders and non-responders [6, 30]. b Kaplan-Meier estimates of survival

MACE, prediction of MACE was not the aim. However, as the true endpoint of CRT is reduction of MACE, surrogate markers must be assessed on their capacity to discriminate between patients with high and low risk for future MACE $[8,9,14]$. In addition, a surrogate marker is a variable reflecting a change, for it should measure an effect of the delivered therapy [7].

When assessing risk of MACE independent of the effect of CRT, absolute values should also be taken into account, especially in the ischaemic cardiomyopathy group. In that case, besides $\triangle$ LVESV, also creatinine levels and peak $\mathrm{VO}_{2}$ at 6 months were demonstrated to be independent predictors of MACE. Both renal function and peak $\mathrm{VO}_{2}$ have prognostic value in heart failure patients [26-28].

Analysis was performed excluding appropriate ICD shocks as part of MACE. The discriminative value of $\triangle$ LVESV concerning the whole population, non-ischaemic and ischaemic cardiomyopathy subpopulations, did not significantly change (results not shown).

\section{Limitations}

This study was a retrospective single-centre study with its inherent limitations. However, our cohort comprised a rather large number of patients, and MACE after 6 months occurred in $19 \%$ of this cohort. MACE occurring before 6 months were not taken into account for this analysis, although these might show a relation with surrogate markers at 6 months. However, the first 6 months are a more instable phase as the effect of CRT might not yet be complete. In addition, the aim of the current study was to assess which surrogate marker at 6 months could best discriminate between patients who did and who did not encounter a MACE in the period thereafter. Moreover, LVESV and LVEF were assessed by echocardiograph. Recently De Haan et al. [29] demonstrated that eligibility to CRT depends on the imag-

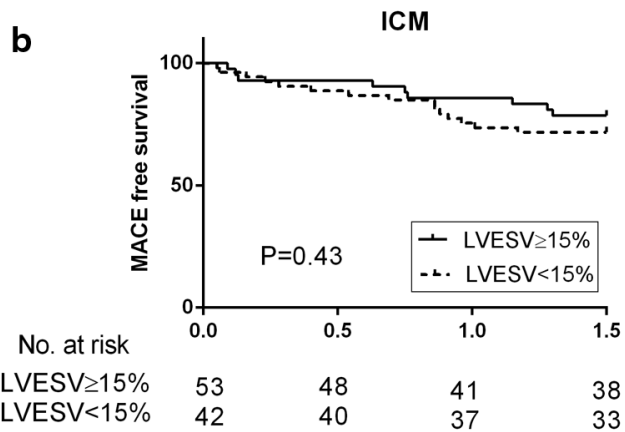

in ischaemic subjects stratified by amount of left ventricular end systolic volume decrease. A $15 \%$ cut-off for $\triangle \mathrm{LVESV}$ was chosen, as this is the most often used cut-off value to discriminate between responders and non-responders $[6,30]$

ing modality applied. This could also be true for assessment of response. This should be investigated in future research.

\section{Conclusion}

$\triangle$ LVESV is the most reliable surrogate marker for CRT response in the total population. This is attributed to the non-ischaemic cardiomyopathy subpopulation in which $\triangle$ LVESV showed an excellent correlation with long-term outcome. On the other hand, for ischaemic cardiomyopathy $\triangle$ LVESV showed a poor correlation with long-term outcome. Therefore cardiologists should be careful using volumetric response as a prognostic marker in ischaemic cardiomyopathy.

Funding None.

Conflict of interest None declared.

Open Access This article is distributed under the terms of the Creative Commons Attribution License which permits any use, distribution, and reproduction in any medium, provided the original author(s) and the source are credited.

\section{References}

1. Cleland JG, Daubert JC, Erdmann E, et al. The effect of cardiac resynchronization on morbidity and mortality in heart failure. $\mathrm{N}$ Engl J Med. 2005;352(15):1539-49.

2. Daubert C, Gold MR, Abraham WT, et al. Prevention of disease progression by cardiac resynchronization therapy in patients with asymptomatic or mildly symptomatic left ventricular dysfunction: insights from the European Cohort of the REVERSE (Resynchronization Reverses Remodeling in Systolic Left Ventricular Dysfunction) trial. J Am Coll Cardiol. 2009;20:1837-46.

3. Wall EE van der. Invasive treatment of patients with cardiomyopathy: CRT-ICD better than ICD alone. Neth Heart J. 2009;17:455. 
4. Manne M, Rickard J, Varma N, Chung MK, Tchou P. Normalization of left ventricular ejection fraction after cardiac resynchronization therapy also normalizes survival. Pacing Clin Electrophysiol. 2013;8:970-7.

5. Rickard J, Cheng A, Spragg D, et al. Durability of survival effect of cardiac resynchronization therapy by level of left ventricular functional improvement: fate of "Non-Responders". Heart Rhythm. 2014;11:412-6.

6. Chung ES, Leon AR, Tavazzi L, et al. Results of the predictors of response to CRT (PROSPECT) trial. Circulation. 2008;20:2608-16.

7. Lipicky R, Packer M. Role of surrogate end points in the evaluation of drugs for heart failure. J Am Coll Cardiol. 1993;22:179A-84A.

8. Yu CM, Bleeker GB, Fung JW, et al. Left ventricular reverse remodeling but not clinical improvement predicts long-term survival after cardiac resynchronization therapy. Circulation. 2005; 11:1580-6.

9. Foley PWX, Chalil S, Khadjooi K, Irwin N, Smith REA, Leyva F. Left ventricular reverse remodelling, long-term clinical outcome, and mode of death after cardiac resynchronization therapy. Eur J Heart Fail. 2011;13:43-51.

10. Mor-Avi V, Lang RM, Badano LP, et al. Current and evolving echocardiographic techniques for the quantitative evaluation of cardiac mechanics: ASE/EAE Consensus statement on methodology and indications endorsed by the japanese society of echocardiography. Eur J Echocardiogr. 2011;12:167-205.

11. Mezzani A, Agostoni P, Cohen-Solal A, et al. Standards for the use of cardiopulmonary exercise testing for the functional evaluation of cardiac patients: a report from the Exercise Physiology Section of the European Association for Cardiovascular Prevention and Rehabilitation. Eur J Cardiovasc Prev Rehabil. 2009;16:249-67.

12. Bristow MR, Saxon LA, Boehmer J, et al. Cardiac-Resynchronization Therapy with or without an Implantable Defibrillator in Advanced Chronic Heart Failure. N Engl J Med. 2004;21:2140-50.

13. Abraham WT, Young JB, León AR, et al. Effects of cardiac resynchronization on disease progression in patients with left ventricular systolic dysfunction, an indication for an implantable cardioverter-defibrillator, and mildly symptomatic chronic heart failure. Circulation. 2004;18:2864-8.

14. Foley PWX, Leyva F, Frenneaux MP. What is treatment success in cardiac resynchronization therapy? Europace. 2009;11(Suppl 5):v58-65.

15. Cohn JN, Ferrari R, Sharpe N. Cardiac remodeling-concepts and clinical implications: a consensus paper from an international forum on cardiac remodeling. J Am Coll Cardiol. 2000;35:569-82.

16. Authors/Task Force Members, Brignole M, Auricchio A, BaronEsquivias G, et al. 2013 ESC Guidelines on cardiac pacing and cardiac resynchronization therapy: the task force on cardiac pacing and resynchronization therapy of the European Society of Cardiology (ESC). Developed in collaboration with the European Heart Rhythm Association (EHRA). Eur Heart J. 2013;34:2281-329.
17. Wall EE van der. Improvement in CRT: new strategies, better choices. Neth Heart J. 2014;22:413-4.

18. Kavanagh T, Myers MG, Baigrie RS, Mertens DJ, Sawyer P, Shephard RJ. Quality of life and cardiorespiratory function in chronic heart failure: effects of 12 months' aerobic training. Heart. 1996;76:42-9.

19. Bruins S, Fokkema MR, Römer JWP, et al. High intraindividual variation of B-Type Natriuretic Peptide (BNP) and Amino-Terminal proBNP in patients with stable chronic heart failure. Clin Chem. 2004;50:2052-8.

20. Schaera BA, Hitza L, Sticherlinga $C$, et al. Changes in renal function over time in patients with cardiac resynchronisation therapy. Swiss Med Wkly. 2013;143:w13863.

21. Felker GM, Shaw LK, O'Connor CM. A standardized definition of ischemic cardiomyopathy for use in clinical research. J Am Coll Cardiol. 2002;39:210-8.

22. Kelle S, Roes SD, Klein C, et al. Prognostic value of myocardial infarct size and contractile reserve using magnetic resonance imaging. J Am Coll Cardiol. 2009;54:1770-7.

23. Bold AJ de, Bruneau BG, Kuoski Bold ML de. Mechanical and neuroendocrine regulation of the endocrine heart. Cardiovasc Res. 1996;31:7-18.

24. Delgado V, Van Bommel RJ, Bertini M, et al. Relative merits of left ventricular dyssynchrony, left ventricular lead position, and myocardial scar to predict long-term survival of ischemic heart failure patients undergoing cardiac resynchronization therapy. Circulation. 2011;123:70-8.

25. Steg P, Bhatt DL, Wilson PF, et al. One-year cardiovascular event rates in outpatients with atherothrombosis. JAMA. 2007;297:1197-206.

26. Stelken AM, Younis LT, Jennison SH, et al. Prognostic value of cardiopulmonary exercise testing using percent achieved of predicted peak oxygen uptake for patients with ischemic and dilated cardiomyopathy. J Am Coll Cardiol. 1996;27:353-7.

27. Hillege HL, Girbes ARJ, Kam PJ de, et al. Renal function, neurohormonal activation, and survival in patients with chronic heart failure. Circulation. 2000;102:203-10.

28. Verhagen MP, Boven N van, Ruiter JH, Kimman GJ, Tahapary GJ, Umans VA. Follow-up of implantable cardioverter-defibrillator therapy: comparison of coronary artery disease and dilated cardiomyopathy. Neth Heart J. 2014;22:431-7.

29. Haan S de, Boer K de, Commandeur J, Beek AM, Rossum AC van, Allaart CP. Assessment of left ventricular ejection fraction in patients eligible for ICD therapy: discrepancy between cardiac magnetic resonance imaging and 2D echocardiography. Neth Heart J. 2014;22:449-55.

30. De Boeck BW, Teske AJ, Meine M, et al. Septal rebound stretch reflects the functional substrate to cardiac resynchronization therapy and predicts volumetric and neurohormonal response. Eur J Heart Fail. 2009;9:863-71. 


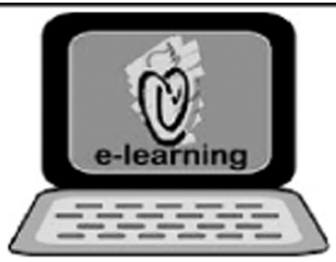

\section{CVOI E-learning formula!}

This is the CVOI e-learning article. The author has prepared 10 questions which are available through the website of the Cardiovascular Educational Institute (CVOI). Please follow the instructions below.

After finishing the questions you will be asked to fill in your name, hospital and e-mail address; then press the button 'verzenden'.

When 6 out of the 10 questions are answered correctly, you acquire 1 accreditation point granted by the Quality Committee of the Netherlands Society of Cardiology (NVVC). The acquired point will be credited to your personal file in the GAIA system. You will also receive an e-mail with all the correct answers.

Over a period of one year 10 e-learning articles will appear in 10 subsequent $\mathrm{NHJ}$ editions. In each edition the e-learning article will be recognisable by a special icon. On an annual basis you can collect 10 accreditation points. The accreditation points are credited in the GAIA system by the CVOI.

If you need additional information, please contact the CVOI by e-mail: cvoi@cvoi.org or by phone: 030-2345001.

E.E. van der Wall

Chief editor NHJ
K.B. Schick

Coordinator CVOI 